\title{
WARD CLEATS
}

\section{Cleat Dimensions}

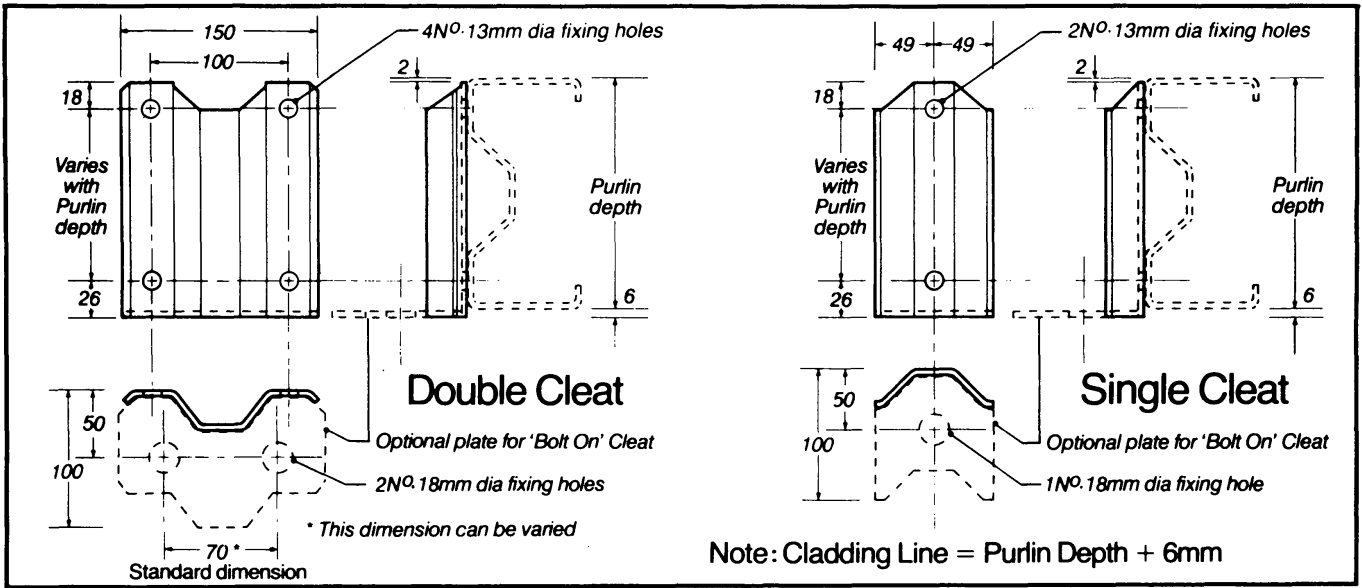

\section{Fixes to all types of building}

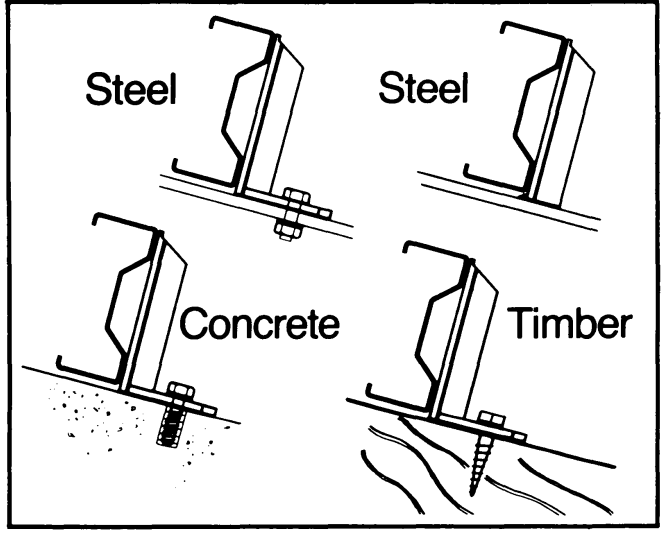

\section{Cleat References}

\begin{tabular}{|c|c|c|c|c|}
\hline \multirow{2}{*}{$\begin{array}{c}\text { Purlin } \\
\text { Section } \\
\text { Size }\end{array}$} & \multicolumn{4}{|c|}{ Application } \\
\cline { 2 - 5 } & \multicolumn{2}{|c|}{ Weld On } & \multicolumn{2}{c|}{ Bolt On } \\
\hline 120 & Single & Double & Single & Double \\
\hline 140 & CS 12 & CD 12 & CS 12B & CD 12B \\
\hline 170 & CS 17 & CD 14 & CS 14B 17 & CD 14B \\
\hline 200 & CS 20 & CD 20 & CS 20B & CD 17B \\
\hline 230 & CS 23 & CD 23 & CS 23B & CD 23B \\
\hline 260 & CS 26 & CD 26 & CS 26B & CD 26B \\
\hline
\end{tabular}

Bolt On Cleats: For hole centres other than those shown, please contact Ward. 